\title{
Game-theoretic Modeling of Market Participants' Behavior: Case of Russian Adjustable-Rate Bonds with Puts
}

\author{
Vitaly L. Okulov ${ }^{1}$ and Polina S. Zhilina ${ }^{2}$ \\ Graduate School of Management, St. Petersburg State University \\ Russia, 199004, St. Petersburg, Volkhovskiy per., 3 \\ ${ }^{1}$ E-mail: okulov@gsom.spbu.ru \\ ${ }^{2}$ E-mail: st054296@student.spbu.ru
}

\begin{abstract}
Adjustable-Rate Bonds with Puts (ARBP), frequently issued by the Russian companies, give the issuer the right to arbitrarily change the coupon payments on the bonds at certain moments. But at these moments, the investor has the right to force the issuer to redeem the bonds at a face value. These reciprocal actions of the issuer and investors can be considered as a dynamic game. We suggest a game-theoretic model that allow to determine the optimal decisions of the players. These decisions are compared with empirical data.
\end{abstract}

Keywords: dynamic game, optimal decisions, Russian bond market, AdjustableRate Bonds with Puts.

\section{Introduction}

Game-theoretic methods are very effective tool for analyzing various management decisions (Heifetz, 2012). In this article, we try to use these methods to analyze a company's financial decisions regarding a very specific loan agreement. The essence of the decisions under consideration is a unilateral arbitrary change by the company of previously agreed payments to creditors, which directly affects their future wealth. However, under the terms of this loan agreement, creditors in return have the right to demand immediate redeem of the nominal amount of debt from the company, which in turn will affect the company's wealth.

These mutual actions can be considered as a game of two players: the debt issuing company and the creditors (or investors); and at first glance this game cannot bring the company any additional benefits in a perfect and efficient market. ${ }^{1}$ This directly follows from an extended interpretation of the Modigliani-Miller proposition (Brealey et al., 2011, Chap.13): the total market value of a company does not depend on the combination of debt securities issued by the company.

Of course, the assumption about market efficiency is a deep abstraction, participants in financial markets have different information and different ideas about the future, they have different attitudes to risks. In addition, any deals are accompanied by transaction costs, so it is unlikely that the Issuer's decision to change the contract is just an adjustment in accordance with new market conditions. We believe that in this game, the issuer is trying to use the imperfection and inefficiency of the market in order to get benefits for account of investors.

\footnotetext{
${ }^{1}$ In a simplified form, the market is perfect if any deal can be made instantly and without additional costs. A perfect market is efficient if all participants are equally informed and have the same capabilities.
} 
The consequence of market inefficiency is the heterogeneity of participants, in fact, this game involves not two, but many players: each investor decides based on their own benefit, and the issuer acts by anticipating the sum of investors' decisions. Another aspect of this game is that markets are highly volatile, and players evaluate their current state based on market changes and emerging opportunities. It is the change in market conditions compared to what was observed at the time of debt issue that provokes the company's desire "to play" to improve its welfare. The aim of this paper is to analyze this very interesting game situation, which is often occur in the Russian financial market.

The structure of the paper is as follows. Since loan agreements on the market are issued in the form of securities (bonds), we first present a brief overview of the various types of bonds issued by companies and pricing models for these bonds. Then, using the example of a large Russian company, we consider the features of specific bonds in which the issuer plays the game with investors. In Russia such bonds are briefly referred to as "bonds with offer", we will use another term - "adjustablerate bonds with puts" or ARBP for short. Next, we analyze the issuer's decision to change payments on the bonds and the investors' decisions to present or not their bonds to the issuer for redemption at the face value, considering these actions as a two-step dynamic game. The proposed game-theoretic model of market participants' behavior allowed us to find optimal decisions for players. These decisions are compared with the empirical results of games played by companies and investors in the Russian market. In conclusion, we briefly discuss the possibility of practical application of the constructed model and the line of further research.

\section{Bonds as an Agreement Between Issuer and Investor}

A corporate bond is a debt security issued by a company (issuer). In essence, it is an obligation to pay a certain nominal amount (face value) to the owner of this security (investor) on a specific date (maturity date). In addition to the face value, the issuer undertakes to make recurring interim payments - coupons. Normally, the date and the amount of these payments are stated by the issuer at the issuance time. Thus, it is a straight bond with a fixed coupon. After the issuing, the bonds are actively traded in the market and the market price $P(t)$ of the bond at any date is completely determined by the future payments, i.e. coupons (Fabozzi, 2007a, Chap.5):

$$
P_{t}=\sum_{i} \frac{C_{t_{i}}}{(1+Y)^{\left(t_{i}-t\right)}}+\frac{N}{(1+Y)^{(T-t)}}
$$

where $N$ and $T$ denote the face value and the maturity date, $t_{i}$ and $C_{t_{i}}$ are the date and the amount of the remaining coupon payments, $\left(t_{i}-t\right)$ states for the time (in years) before each of the remaining coupons. The date of the last coupon payment typically coincides with the maturity date of the bond.

In this formula, linking the market price of the bond $P_{t}$ and its parameters $(N$, $T, C_{t_{i}}, t_{i}$ ), yield to maturity $Y$ is the only calculated parameter. Usually, at the issuance time the issuer sets coupons in such amount that the market price $P$ of the security was close to its face value $N$.

Market fluctuations in supply and demand lead to daily changes in market prices and, therefore, in yields respectively. In order to moderate price fluctuations, the companies often choose issuing floating-rate bonds or floaters instead of bonds with fixed coupons. Such issues imply that coupon payment dates are fixed but the value 
of future coupons is tied to an observable basic market indicator. Most often, this is the interest rate on the interbank loan market (for example, the 6-month LIBOR). It is important that the functional relation between the value of the future coupon and the value of the market indicator is explicitly defined in the prospectus, therefore, neither the issuer nor investors can influence the value of coupons in any way. The pricing model for such bonds is more complex and requires understanding of how basic market indicators can change in the future (Ramaswamy, Sundaresan, 1986). The relation (1) remains technically valid if we insert the expected values of coupon payments into it.

Bonds are issued for a long term, and till the maturity the situation both in the market and in the company can change dramatically. For example, according to changes in the money supply policy in the country, interest rates will decline sharply. Then the issuer will regret that his coupons are too large compared to those that he could set issuing bonds now. Taking this into consideration, the issuer states such condition in the prospectus that gives him the right to pay off the entire issue earlier. These debt securities are defined as callable bonds or bonds with an embedded call option for the issuer. Moreover, companies embed the right to early redemption in bonds in the hope that business will go well in the future, and the company will be able to pay off its debt ahead of schedule.

In contrast, if interest rates in the country rise, or business don't go well in the company, then the price of the bond will drop sharply, and investors will in turn regret that they initially bought these bonds at a price close to face value. In order to reduce such risks for investors and increase the demand for the bonds, the company give investors the right to sell the bonds to the issuer at par on specific dates. Therefore, these bonds are puttable or bonds with an embedded put option for an investor.

There are several quite complex pricing models for bonds with embedded options (Fabozzi, 2007b, Chap.9). It is important that the decision of one side (either the issuer or investors) made at the option exercise time is completely determined by the current market situation, and the other side can not affect it in any way. Therefore, a gaming situation cannot occur in case of any above-mentioned types of bonds.

However, a game may arise when the bond issue includes a combination of call-put options, i.e. both the issuer and the investor have the right to change the terms of the agreement. For example, a stochastic game approach was used in (Ochiai and Ohnishi, 2015) to analyze the bond with embedded call and put options. Another exotic type of bond (Variable-Rate Demand Bond or VRDB) is discussed in (Hooper, Pointon, 2019). These floating-rate bond that can be sold back to the issuer have not been studied enough yet.

Straight bonds are well known in the Russian market, however, floaters and bonds with embedded options are quite rare. Mostly due to the fact that Russian investors did not have adequate understanding of these complex bonds pricing until recently. Therefore, the investors were not prone to buy these underestimated securities and for the issuers it was beside the purpose to issue them. Some examples are given in (Bukhvalov et al., 2015, Chap.6). Nonetheless, one type of the bonds with highly complex structure unparalleled in developed markets are widely distributed in Russian market. These bonds are called Adjustable-Rate Bonds with Puts (ARBP). Although there are no recognized pricing models for such bonds, over 
the past decade alone Russian companies have issued more than 400 such issues, and their total volume exceeded $\$ 40$ billion.

\section{Put Option in ARBP as a Dynamic Game Between Issuer and Investors}

According to the terms of ARBP issuance, the issuer has the right to establish a new value of coupon payments at specific dates completely arbitrarily. Increasing the remaining coupons and reducing them to zero are both possible. Such arbitrariness can obviously affect the market price of the bond dramatically and damage investors' wealth. However, on the same dates the investors have the right to sell their bonds (put option) to the issuer at par. Thus, this arbitrary decision of the issuer initiates a response from investors. If the issuer decides to cut coupons to zero, then all the investors will demand a redemption of bonds. Then the issuer may face financial difficulties and will be forced to borrow money urgently. In case the issuer decides to increase coupon payments, many investors surely decide to keep bonds further. Still, the issuer has to pay a high coupon until maturity, which is costly and disadvantageous for him. In other words, the issuer should predict the investors' response to his decision on coupon payments adjustment.

The implementation mechanism of the participants' decisions described above might be given on the example of the bond issue RU000A0JQXE5 of ALROSA, the world's largest diamond-mining company. These bonds with quarterly coupon payments were placed among investors on June 29, 2010, the maturity date of the bonds came on June 23, 2015. The issue volume amounted to 8 billion rubles (about $\$ 250$ million). The coupon rate of $8.25 \%$ per annum was set only for first 12 coupon periods. Therefore, on June 11, 2013, the company had to make a decision on the new rate for all of the following coupon payments. In turn, the bondholders had the right to demand the redemption at par from June 15 to June 25, 2013, and the issuer was obliged to redeem the bonds on the demand. On June 11, 2013, the issuer set a negligible rate of $0.1 \%$ per annum for all the coupon periods until maturity, as a result, investors responded with divestiture of $99.5 \%$ of the bonds. Such extreme decisions of the issuer are not uncommon; however, it should be noted that most issuers prefer to change coupons less radically.

What are the reasons of the issuer's decision to adjust the coupon rate? At first, this may occur due to a change in the overall market situation. If interest rates fall, the company will not want to pay more than other borrowers and will reduce the remaining coupons. Otherwise, when interest rates rise, the company will also have to increase coupons in order to avoid the situation when many investors exercise put option and the necessity to immediately seek money for a buyback, which can be very costly.

Secondly, it is possible for the company to amass such sums of money that there is no longer a need to recourse to borrowing. Then the redemption of all the bonds will be favorable due to absence of interest payments. Of course, in this case, the issuer reduces the coupon to zero, regardless of how the overall market situation has changed. Conversely, if the company does not have money to buy bonds back at par, it can even increase coupons. However, this can rise investors' concern and bondholders will demand the redemption which will further worsen the financial position of the company. 
What reasons can affect the investor's decision on keeping the bond or demanding its redemption? Firstly, if it seems to the investor that the change in the coupon by the issuer does not correspond to the overall market situation. Then the investor will sell the company their bonds at par and immediately buy the other debt securities. Secondly, each investor may have his own reasons. For example, in case of urgent need for money he will demand bonds redemption regardless the issuer's decision on coupon rate adjustment.

\section{Game-theoretic Modeling of Players' Decisions}

Consider a simple model. Suppose that at the moment $t=0$ the company (issuer) decided to raise funding and placed $n$ bonds with par value $N$ with yearly coupon payments until maturity in $T=2$ years. ${ }^{2}$ The issuer provided investors with a put option in a year $\left(t_{1}=1\right)$, therefore, the coupon $C_{2}$ for the second period was not defined at the time of issuance. Suppose that at the moment $t=0$ the observed risk-free interest rate was $R F_{0}$ for any duration. Then, given the possibility of bankruptcy of the company, investors want to lend to the issuer at a higher rate $R F_{0}+R C$, where $R C$ denotes the so-called the issuer's credit spread.

Let the issuer has set the coupon $C_{1}=N \cdot\left(R F_{0}+R C\right)$ for the first period, before the put option exercise. Under the described market conditions, by virtue of the Pure Expectations Hypothesis (Campbell et al., 1997, Chap.10), it can be claimed that the expected value of the second coupon is $E\left[C_{2}\right]=C_{1}$. Applying these values to the relation (1), the initial issue price is at par and bonds' yield to maturity is $Y_{0}=R F_{0}+R C$. This is a fair yield on the debt security taking into account the issuer's credit risk.

Let us consider and analyze what happens right before the put exercise $\left(t=t_{1}\right)$. Suppose the market situation change and the risk-free interest rate becomes equal $R F_{1}$, however, credit spread $R C$ remains the same, i.e. the financial position of the company has not improved and has not worsened. From (1) it is clear that those investors who want to demand the redemption of their bonds in any case, estimate the value in the amount $P_{t=1}=C_{1}+N$. Then, those investors who choose to hold the bond for next year until maturity will value it in an amount equal to

$$
P_{t=1}^{*}=C_{1}+\left(N+C_{2}\right) /\left(1+Y_{1}\right)
$$

where $C_{2}$ is still remaining undefined coupon for the second year, though going to be set soon, and $Y_{1}=R F_{1}+R C$ is the fair yield taking into account the issuer's credit risk at $t=t_{1}$.

If the issuer sets the coupon $C_{2}$ less than $N \cdot Y_{1}$, then $P_{t=1}^{*}<P_{t=1}$. Therefore, all rational investors will exercise the right to sell the bonds to the issuer at par. In case of $C_{2}>N \cdot Y_{1}$, it is obvious that $P_{t=1}^{*}>P_{t=1}$. Undoubtedly, even those investors who wanted to exercise put option would rather not to and would instead sell the bonds on the market. Thus, under the current market conditions, the coupon $C_{2 e q}=N \cdot Y_{1}$ is considered to be fair to the investors as all of them evaluate bonds equally, i.e. $P_{t=1}=P_{t=1}^{*}$. With such a coupon all investors will continue to hold bonds, since the purchase and/or sale of a bond is disadvantageous due to transaction costs. This is the traditional approach to analyze ARBPs which factually equates these bonds to floaters, i.e. bonds tied to the current risk-free interest rate.

\footnotetext{
${ }^{2}$ The amount $n \cdot N$ is called the issue volume.
} 
Now consider the problem as a dynamic game between issuer and investors.

Model 1. Firstly, we assume that the financial markets are perfect: any financial transactions are available, performed instantly and do involve related costs. Suppose that at the time $t=t_{1}$, the overall market situation has changed, and the risk-free rate has become equal $R F_{1}$.

Suppose the issuer decide to establish a coupon in the amount of $C_{2}$. For convenience, we denote the issuer's decision as $C_{2} / N$ which is a coupon rate. There is a reasonable condition $0 \leq C_{2} / N<1$, although a bond coupon is far less than the face value in practice. Let $b$ denote that proportion of the issue that is redeemed on investors' demand $0 \leq b \leq 1$, then $1-b$ is remaining part that investors hold until maturity.

Investors demanding the redemption of $b \cdot n$ number of bonds will receive the amount $b \cdot n \cdot N$ and immediately buy bonds with a maturity of 1 year issued by other companies with the same credit rating in the market. At $t=2$ these bondholders will receive $b \cdot n \cdot N \cdot\left(1+R F_{1}+R C\right)=b \cdot n \cdot N \cdot Y_{1}$. Those investors who do not exercise put option will get $(1-b) \cdot n \cdot\left(N+C_{2}\right)$ at the same time $t=2$. Then the investor's payoff function per unit of money invested during the initial placement can be defined as:

$$
V_{\text {in }}\left(b, C_{2} / N\right)=b \cdot Y_{1}+(1-b) \cdot C_{2} / N .
$$

Calculating the costs of the issuer, as they redeem a part of the issue, they have to pay the amount $b \cdot n \cdot N$. The issuer, therefore, needs to offset the resulted shortage of funds by additional borrowings. Consequently, he will have to return the amount of the loan and pay interest on the fair rate $R F_{1}+R C=Y_{1}$ in a year. For the bonds the investors continue to hold, the issuer will pay the amounts of $(1-b) \cdot n \cdot\left(N+C_{2}\right)$. As a result, the payoff function of the issuer per unit of money can be written as:

$$
V_{i s}\left(b, C_{2} / N\right)=-b \cdot Y_{1}-(1-b) \cdot C_{2} / N .
$$

This is a zero sum two-person game. Hence, players' optimal decisions can be found from first-order conditions (Petrosyan et al., 2012):

$$
\frac{\partial V_{i s}}{\partial\left(C_{2} / N\right)}=0 ; \frac{\partial V_{i n}}{\partial b}=0,
$$

wherefrom the solutions are

$$
\left(C_{2} / N\right)_{o p t}=Y_{1} ; b_{o p t}=1 .
$$

The formulas (4) give a solution different from the traditional one. The issuer establishes a fair coupon $C_{2}=N \cdot Y_{1}$, and all the investors demand the bonds redemption.

In the Russian market, this game between issuers and investors has occurred many times. It can be assumed that players have learned to make optimal decisions by trial and error. In practice, optimal solutions (4) are rarely observed in the case of ARBPs. Consider the empirical data on 366 ARBPs issued in the period 2010-2019. In our analysis we did not examine those bonds which placement and puts took place in December 2014 and January 2015, as due to the crisis the interest rates in the market have been abnormally high at that time. In addition, the ARBPs where 
issuers set an excessively low coupon rate (less than $0.1 \%$ ) have been excluded. For our analysis MosPrime rates for a period of 6 months have been taken as risk-free interest rates.

If we interpret the issuer's decision as a change in the previously established coupon rate, then we readily get empirically verifiable expression $\left(C_{2} / N\right)_{\text {opt }}-$ $C_{1} / N=R F_{1}-R F_{0}$ from (4). In Fig. 1 the actual decisions of issuers to change the coupon rate $\Delta C R_{a c t}=\left(C_{2} / N\right)_{a c t}-C_{1} / N$ are compared to model predictions $\Delta C R_{\text {mod }}=\left(C_{2} / N\right)_{\text {opt }}-C_{1} / N=R F_{1}-R F_{0}$. As can be seen in the figure, there is a tendency to change the coupon rate in accordance with the changing market situation. Nevertheless, there are also noticeable differences between actual and model predictions, and a significant scatter of points relative to the line $y=x$.

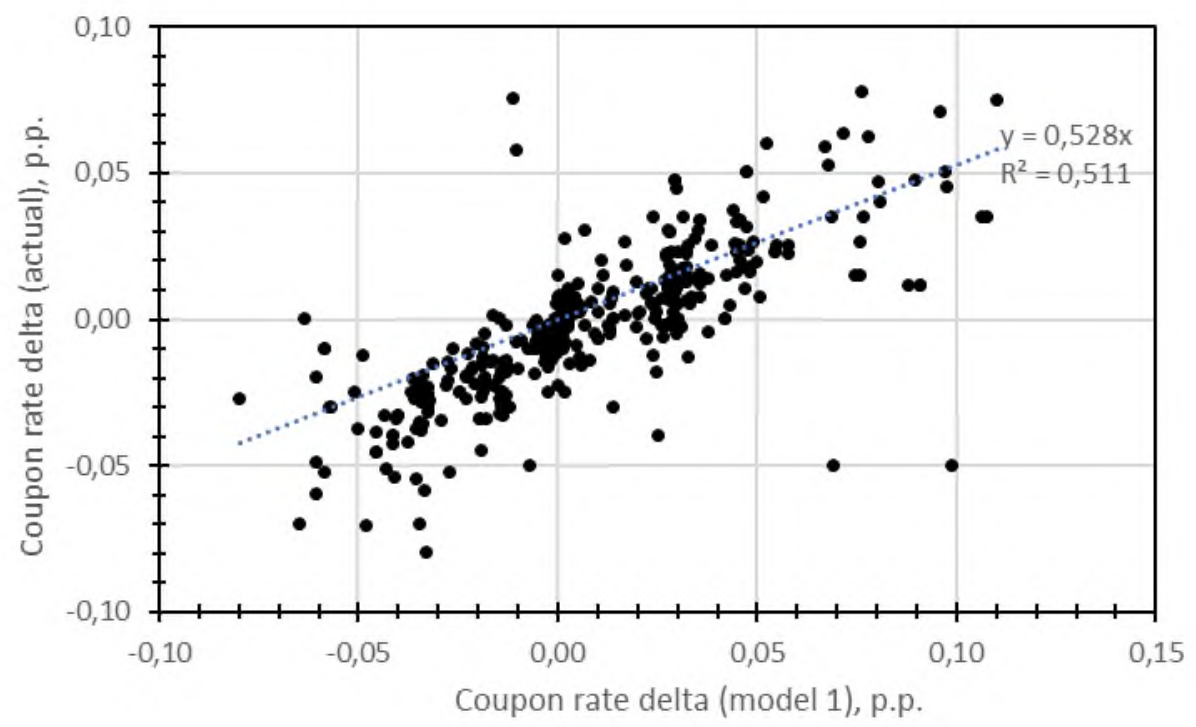

Fig. 1. Decisions made by issuers and predicted by model 1. dotted line is a linear approximation of empirical points.

While the issuer's decisions somehow agree with the predictions (4), the considered simple model cannot explain the actions of investors. Fig. 2 shows the issues shares of repurchased bonds depending on the value $\left(C_{2} / N\right)_{a c t}-\left(C_{2} / N\right)_{\text {opt }}$. We see that on average the share of repurchased bonds is almost random and does not depend on the issuer's decision. Even if the issuer has raised the coupon rate in excess of the optimal level, there are many investors who have demanded bonds redemption. In particular, as a response to a high coupon (102 ARBPs) in 26 cases the share of repurchased bonds was above 0.5. Although this fact can be explained by the investor's desire to receive money immediately, it is difficult to explain the situation when, in response to lowering rates below the optimal level, investors continued to keep a large proportion of bonds at a loss. In case of 263 ARBPs the issuer fixed the rate below the optimum level, and only in the 98 cases the proportion of repurchased bonds was greater than 0.5 . 


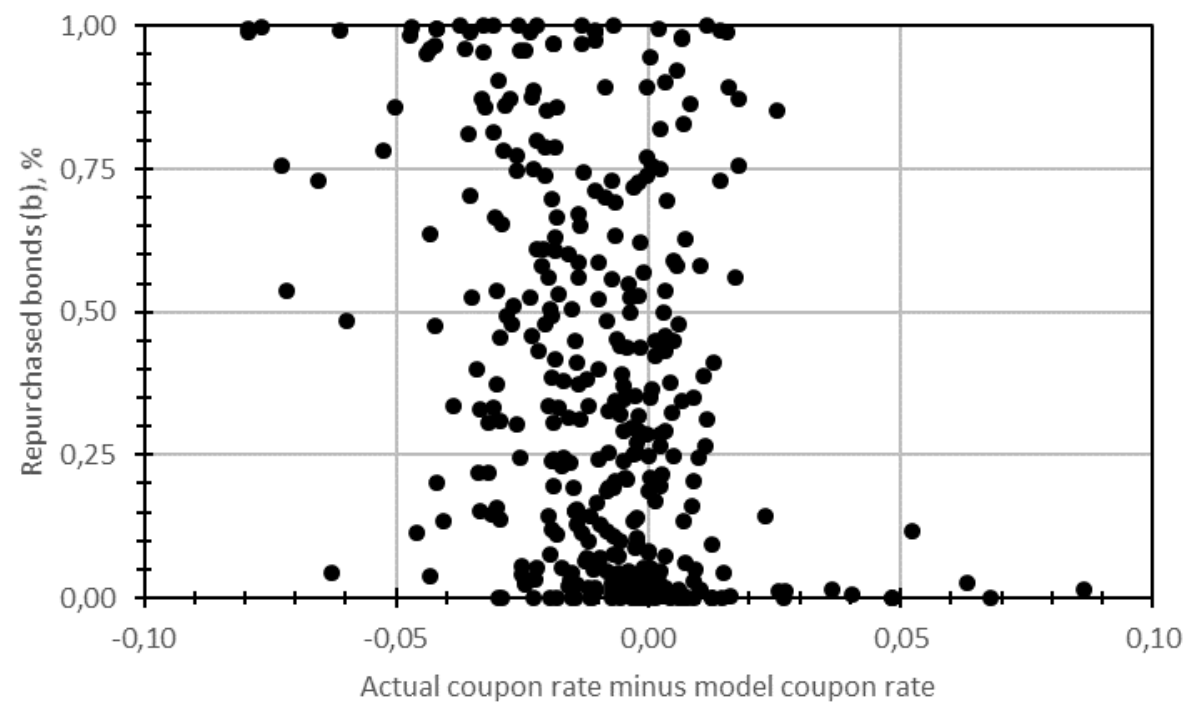

Fig. 2. Issuer's decision and proportion of repurchased bonds.

Model 2. Probably, an explanation for this mismatch between the model conclusions and the reality are to be found in the imperfection and inefficiency of the market. For example, if investors have different information, their perception of fair yield $Y_{1}$ may vary. The issuer does not know what value $Y_{1 i}$ a particular investor $i$ focuses on, therefore, the value $Y_{1 i}$ is actually an unobservable (random) for the issuer. However, the issuer may at least partly assess the distribution and the range of definition of this random variable, by, for example, observing of bond price quotation $^{3}$ at the moment $t=t_{1}$. Therefore, we consider that all participants in the game know the minimum and maximum values $Y_{1 i}$.

Based on these assumptions, the game can be formulated as follows.

1. Every $i$ investor owns one bond. He gets information about the issuer's decision $C_{2} / N$ and in response chooses such strategy $b_{i}$ that maximizes the following payoff function:

$$
V_{i n, i}\left(b_{i}, C_{2} / N\right)=b_{i} \cdot Y_{1 i}+\left(1-b_{i}\right) \cdot C_{2} / N,
$$

where $b_{i}$ equals either 0 (the investor holds the bond) or 1 (exercises the put option); $Y_{1 i}$ denotes the investor's understanding of fair yield of the bond. The expression (5) implies that the investor may exercise put and use the obtained money to immediately buy another issuer's bonds, the yield of which seems fair to him. If he holds a bond, he will receive a coupon yield $C_{2} / N$.

If for a given investor $Y_{1 i}>C_{2} / N$, then $b_{i}=1$. However, for another investor $j$ it is possible that $Y_{1 j}<C_{2} / N$, therefore, his strategy is $b_{j}=0$ by the same issuer's decision $C_{2} / N$. As there is a sum of the decisions made by investors $b=\sum_{i} b_{i}$ in the game on the whole, then in case of any issuer's strategy in range $Y_{1 \min } \leq C_{2} / N \leq$

\footnotetext{
${ }^{3}$ Quoted prices are the best current prices for the purchase (bid) and sale (ask) on the exchange.
} 
$Y_{1 \max }$ the proportion of repurchased bonds for the whole issue is between 0 and 1 $(0<b<1)$.

Suppose that all investors' perceptions of fair yield are evenly distributed over a range of values $Y_{1 \min } \leq Y_{1 i} \leq Y_{1 \max }$. Suppose that the issuer has chosen $C_{2} / N$ from the range $Y_{1 \min } \leq C_{2} / N \leq Y_{1 \max }$, then we can readily show that the resulting solution for all investors will be as follows:

$$
b=\frac{Y_{1 \max }-C_{2} / N}{Y_{1 \max }-Y_{1 \min }} .
$$

2. Suppose the issuer knows the distribution of $Y_{1 i}$ for bondholders. In addition, the player knows his true financial state, and therefore, the fair yield of his bonds $Y_{1 i s}$ from the range $Y_{1 \min } \leq Y_{1 i s} \leq Y_{1 \max }$. The issuer refinances all bonds repurchased at the expense of a new debt, the yield of which is $Y_{1 i s}$. He pays the coupon yield $C_{2} / N$ on the remaining bonds. Therefore, taking into account (6), the issuer's payoff function is:

$$
V_{i s}\left(b, C_{2} / N\right)=-\frac{Y_{1 \max }-C_{2} / N}{Y_{1 \max }-Y_{1 \min }} \cdot Y_{1 i s}-\left(1-\frac{Y_{1 \max }-C_{2} / N}{Y_{1 \max }-Y_{1 \min }}\right) \cdot \frac{C_{2}}{N} .
$$

By maximizing this payoff function, we get

$$
\left(C_{2} / N\right)_{o p t}=\left(Y_{1 i s}+Y_{1 m i n}\right) / 2 .
$$

This decision of the issuer gives the proportion of the repurchased bonds equal to

$$
(b)_{\text {opt }}=\frac{\left(Y_{1 \max }-Y_{1 \min }\right)+\left(Y_{1 \max }-Y_{1 i s}\right)}{2\left(Y_{1 \max }-Y_{1 \min }\right)} .
$$

Analyzing expressions (7) and (8), we can draw the following conclusions:

1. The proportion of repurchased bonds may vary from $b=1$ when the issuer's strategy is $C_{2} / N=Y_{1 \min }$ to $b=0,5$ when $C_{2} / N=Y_{1 \max }$. Undoubtedly, if $C_{2} / N>$ $Y_{1 \max }$ under excepted assumptions we get $b=0$. Thus, this simple model predicts that in practice there should be no ARBPs in which the proportion of repurchased bonds is in the range $0<b<0,5$. However, as can be seen from the Fig. 1 , such a situation is very common. Perhaps the assumption of a uniform distribution of fair yield perceptions is too simplistic.

2. Analyzing the investors' perception of fair yield, it is obvious that $Y_{1 \min }>$ $R F_{1}$. Indeed, fair yield cannot be lower than the risk-free rate currently observed (at the put exercise time). Therefore $Y_{1 \min }=R F_{1}$ is a limiting value. The evaluation of $Y_{1 i s}$ is further carried out under the assumption that the financial condition of the company has not worsened or improved compared to the time of the bond placement. In other words, we believe that the credit spread $R C$ is constant, its value can be estimated on the coupon rate that the issuer offered at placement: $R C=C_{1} / N-R F_{0}$. Thus, $Y_{1 i s}=R F_{1}+C_{1} / N-R F_{0}$, if we apply this expression to $(7)$, we obtain the following relationship:

$$
\left(\frac{C_{2}}{N}\right)_{o p t}-\frac{C_{1}}{N}=R F_{1}-R F_{0}-\frac{1}{2}\left(\frac{C_{1}}{N}-R F_{0}\right) .
$$

This prediction of the model can be compared with the observed changes in coupon rates of ARBPs. Fig.3 shows the issuers' decisions right before the put 
exercise time, wherein x-coordinate for each point $\Delta C R_{\text {mod }}$ is calculated according to the expression in the right side of the equation (9), and the y-ordinate of a point $\Delta C R_{a c t}$ is the actual issuers' decisions: $\left(C_{2} / N\right)_{a c t}-C_{1} / N$. Comparing the graphs in the Fig. 1 and 3, we see that the group of points around the straight line $y=x$ in the Fig.3 is expressed more clearly, that provides an evidence in favor of the 2nd model.

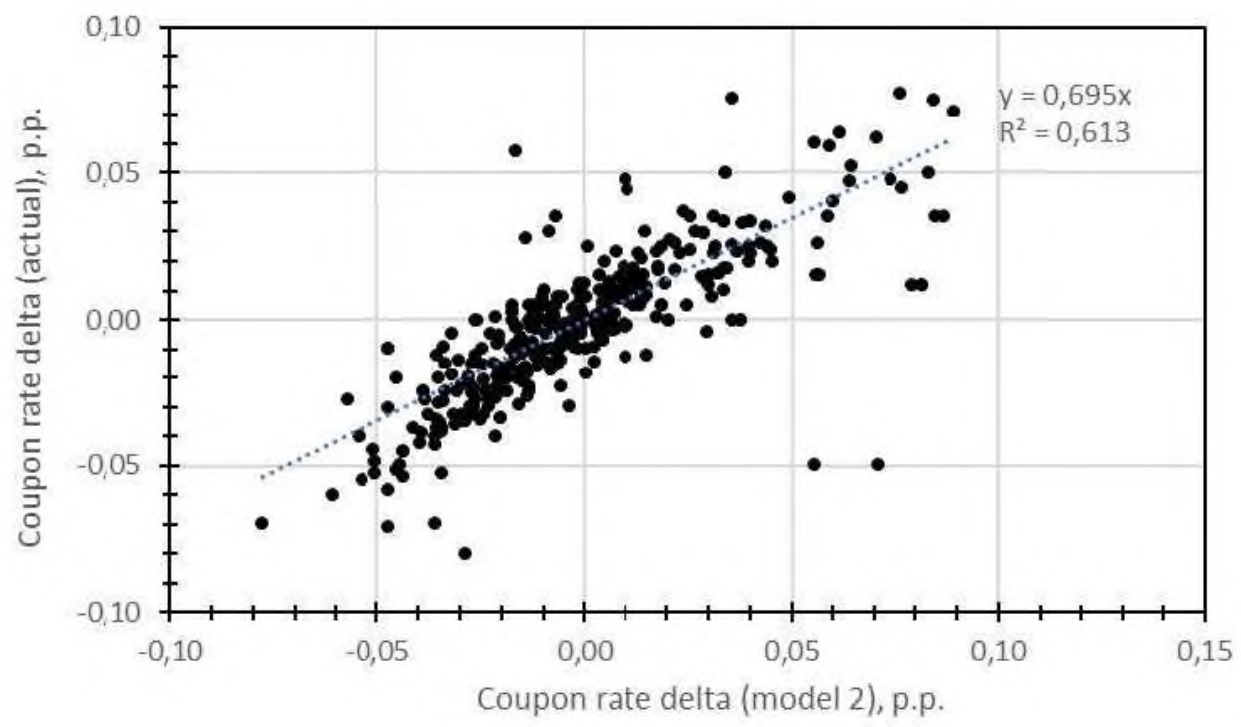

Fig. 3. Decisions made by issuers and predicted by the model 2 . The dotted line is a linear approximation of empirical points.

Expression (9) predicts that the change in coupon rates should be less than the total rate changes in the financial market: $C_{2} / N-C_{1} / N<R F_{1}-R F_{0}$. By installing a relatively low coupon, the issuer benefits, because he reduces his loan costs. In fact, this decrease is due to those investors who are too optimistic about the financial state of the issuing company. This is also clear from expression (7) that the issuer should be guided only by the decisions of investors with optimistic ideas about fair yield. Note that similar motives for the issuer's decisions are discussed in (Amiram et al., 2018).

Basing on the findings of the 2nd model, we estimate the optimal solutions in the important special case of highly liquid, i.e. actively traded, releases of ARBPs. Under the conditions of a liquid market investors obtain quite homogeneous perception of the fair yield, so the values $Y_{1 \min }$ and $Y_{1 \max }$ and the true fair yield $Y_{1 i s}$ are quite close. With a high degree of credibility, it can be agreed that $Y_{1 i s}=$ $\left(Y_{1 \min }+Y_{1 \max }\right) / 2$. In addition, the bid-ask spread of these bonds is typically small, then we suppose that $Y_{1 \max }-Y_{1 \min } \approx(0,1 \div 0,2) \cdot Y_{1 i s}$. Applying these evaluation in (7) and (8), we obtain that $(b)_{o p t}=0,75$ and $\left(C_{2} / N\right)_{\text {opt }} \approx(0,95 \div 0,97) \cdot Y_{1 i s}$.

To conclude the analysis, we should discuss the sanity of the key assumption of the model about the heterogeneous distribution of the investors' fair yield perception. If the financial market is efficient, then all participants are informed about the 
true value of fair yield $Y_{1 i s}$, and the assumption about the heterogeneity of investors' fair yield seems to true by a stretch of imagination. However, if we take into account various market imperfections and possible personal motives of investors, then the assumption made in the article turns out to be even too strict.

Let us consider, for example, what the accounting for transaction costs in repurchases will lead to. The procedure for submission of the bonds for redemption is technically quite complicated and entails additional costs. Under this procedure, the investor must pay a fixed amount to a special financial intermediary, a buyout agent. This amount is proportional to the size of the coupon, therefore, for an investor owning one bond, repurchase is completely unprofitable. If we deduct these costs and repayment of the fair yield $Y_{1 i s}$, then we obtain the yield $Y_{1 i}$ which the investor can expect in case of bonds repurchase. For investors with a small package of bonds, it turns out that $Y_{1 i} \rightarrow 0$. On the other hand, for investors with a very large package of bonds, the relative value of the buyback costs is negligible, therefore, for such investors $Y_{1 i}=Y_{1 i s}$. Thus, the imperfection of the market leads to $Y_{1 \min }=0, Y_{1 \max }=Y_{1 i s}$ in the model. In practice, investors often use their bonds as collateral for a bank or broker, therefore, such investors, in principle, will not be able to participate in the repurchase, and for them $Y_{1 i}=0$.

Still, with such an interpretation of the game parameters, the investor's payoff function will have the form (5), and it is possible to construct a model similar to the 2nd model. However, since the distribution of values $Y_{1 i}$ among investors will be a non-linear increasing function, optimal decisions made by players can considerably change.

\section{Practical Applications of the Model}

A reliable and precise model can indicate the optimal strategy for the issuer and predict the reaction of investors to this decision. However, it is not the only thing that matters. Market participants are more concerned about the problems associated with the information support of the market for these bonds. The main problem is as follows. At present, the agencies that disseminate financial information about ARBPs calculate only the so-called yield to exercise a put option. Thus, they basically assume that all investors will demand bonds redemption. Therefore, this bond has a "shortened" maturity. Accordingly, the yield to put is usually small, and the exposure to interest rate risk (modified duration) of these issues is almost zero.

Such an interpretation of the bond as "short issue" is disadvantageous to both long-term investors and the issuer. If the investor is not going to repurchase bonds, then the indicators of yield and risk of his diversified portfolio will experience a jump at the put option exercise time. The investor might associate this with a specific portfolio risk, which his portfolio actually does not have. As for the issuer, external creditors (banks) can underestimate the issuer's credit ratings on the basis that the structure of its market debts is biased towards short-term issues (as creditors only know about yield to exercise a put).

If the model can predict optimal future decisions in terms of the coupon rate adjustments, then it will be possible to use the equation (1), substituting an unknown future coupon expected optimal solutions. This will allow to evaluate, at any given time, the bonds' yield to maturity, and with yield to put this information will be valuable for all the market participants. 


\section{Conclusion}

Deals in the financial market are often associated with gambling, however, it is not basically a game of participants with each other but a game of a subject with the nature. ARBP is one of the rare cases when one subject (issuer) plays against a group of others (investors). Therefore, the desire to apply the game theory tools to the analysis of their decisions is explainable.

We have proposed and analyzed two simple game models to explain the decisions of the players. The model, built on the assumption of the bond market effectiveness, provides a set of optimal strategies that are far from the decisions observed in the market. The second model, which takes into account imperfections and inefficiencies of the bond market, shows a better veracity.

The proposed models consider an ARBP's put option as a two-step dynamic game, however, in practice, bond issues are provided with several puts at different times. In fact, investors have a choice: to repurchase the bond now or to hold the bond and have the right to exercise the next put. Analysis of the puts as a multistage game is the further area of research.

Another approach to the analysis of the ARBPs may be based on a fundamentally different interpretation of the issuer's payoff function. An ARBP's option may be evaluated as a game of incomplete information: the issuer does not know the investors' payoff function in case he does not know the distribution of $Y_{1 i}$. And if the decision of investors on the whole is a stochastic variable for the issuer, then the gain for it will also be random.

There are two possible approaches to further analysis. Firstly, if the issuer is risk-neutral, he will maximize/minimize the expectation of a financial result, as it was implicitly assumed in the proposed models. Secondly, if the issuer is risk-averse, then the criterion of optimality is the maximization of some function that takes into account both the expected result and the variance of possible results. The issuer's payoff function in this game will be completely different and it is not clear what model results this will lead to. It also may be a subject for research.

Whatever the case, apparently, we can be sure that it is a game theory that can make a significant contribution to understanding the pricing of such bonds. An understandable formula for the price of ARBPs will give a new impetus to these financial instruments and will render invaluable assistance to all market participants.

\section{References}

Amiram, D., A. Kalay, A. Kalay and N. B. Ozel (2018). Information Asymmetry and the Bond Coupon Choice. The Accounting Review, 93(2), 37-59.

Brealey, R. A., S.C. Myers and F. Allen (2011). Does debt policy matter? In: Principles of Corporate Finance, concise edition, $2^{\text {nd }}$ ed., Chap. 13, pp. 324-345. McGrawHill/Irwin.

Bukhvalov, A. V., E. A. Dorofeev and V. L. Okulov (2015). Pricing of floaters. In: Lectures on selected issues of classical financial models (Bukhvalov A.V., ed.), $2^{\text {nd }}$ ed., Chap.6, pp. 171-197. GSOM Publ. Center: St.-Petersburg (in Russian).

Campbell, J. Y., A. W. Lo and A.C. MacKinlay (1997). Fixed-income securities. In: The Econometric of Financial Markets, Chap.10, pp. 395-426. Princeton Univ. Press: Princeton

Fabozzi, F. J. (2007a). Introduction to the valuation of debt securities. In: Fixed Income Analysis, $2^{\text {nd }}$ ed., Chap. 5, pp. 97-118. John Wiley \& Sons: Hoboken. 
Fabozzi, F. J. (2007b). Valuing bonds with embedded options. In: Fixed Income Analysis, $2^{\text {nd }}$ ed., Chap. 9, pp. 215-255. John Wiley \& Sons: Hoboken.

Heifetz, A. (2012). Game Theory: Interactive Strategies in Economics and Management. Cambridge Univ. Press: New York.

Hooper, V. and J. Pointon (2019). A Valuation Model for the Variable Rate Demand Obligation. Journal of Mathematical Finance, 9, 388-393.

Ochiai, N. and M. Ohnishi (2015). Valuation of Game Option Bonds under the Generalized Ho-Lee model: A Stochastic Game Approach. Journal of Mathematical Finance, 5, 412422.

Petrosyan, L. A., N.A. Zenkevich (2016). Game theory, $2^{\text {nd }}$ ed. World Scientific Publ., London-Singapore.

Ramaswamy, K. and S. M. Sundaresan (1986). The valuation of floating rate instruments. Journal of Financial Economics, 17(2), 251-272. 